\title{
A comparison of national specialty societies in Canada: Does CAG measure up?
}

\author{
William G Paterson MD FRCPC \\ President, Canadian Association of Gastroenterology \\ Department of Medicine, Queen's University, Kingston, Ontario
}

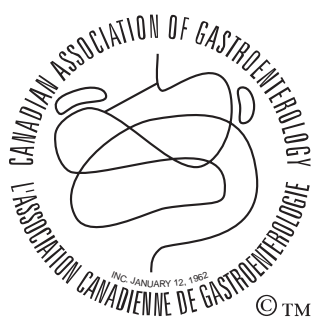

En français voir page 493

T he Federation of National Specialty Societies of Canada (FNSSC) is a formal organization established in 2003 that includes the majority of national medical and/or surgical specialty societies in Canada. Forty-two societies currently comprise the FNSSC, including the Canadian Association of Gastroenterology (CAG). One of the advantages of the FNSSC is that it provides a united voice on specialty concerns to the Canadian Medical Association and the Royal College of Physicians and Surgeons of Canada. Second, it affords a framework for sharing common problems and experiences among member societies, for example, regarding accreditation and funding. Third, its influence may prove useful in securing preferred contracts from suppliers, including hotel chains and insurance companies, for FNSSC associations.

Information-sharing offers an interesting view to how various societies operate and the differences between them. As an example, Table 1 shows the categories and related annual fees for membership for 11 different FNSSC associations. The 11 associations represent organizations that participated in a recent FNSSC survey on annual conference fees (see below), and which illustrate the diversity of membership types and fees.

\section{MEMBERSHIP}

All societies have a category of membership for physicians practicing in the association's specialty within Canada, often termed 'full' or 'active' members. Physician membership fees vary considerably but average approximately $\$ 300$ per year (range $\$ 70$ to $\$ 535$ per year) based on the 21 societies noted below. For physicians of a different specialty, a few organizations offer a discounted 'associate' membership. Reduced fees for allied health care professionals such as nurses and technicians may be offered and are typically less than physician dues but more than resident dues. Resident trainee members are recognized by virtually all societies and either pay a minimal amount (typically $\$ 15$ to $\$ 50$ per year) or are granted free benefits. Undergraduates may have a separate trainee category in which they pay a lesser fee than residents, or receive free membership. Most organizations also describe a type of membership for professionals outside Canada, and less commonly, for international trainees. Benefits are generally free for senior and honorary members. For industry supporters of the society, corporate membership is available for a substantially higher yearly fee of $\$ 1,000$ to $\$ 2,000$. One association even offers a 'spouse' category of membership for spouses of members that confers all benefits apart from journal subscription.

\section{SCIENTIFIC MEETING REGISTRATION}

In 2005, 21 FNSSC societies participated in a survey of practices and costs related to their annual scientific meeting. In the interest of space, findings from 11 societies are presented in Table 2 but clearly illustrate the considerable variability in registration fees. It is worth noting that, apart from the CAG, only one other society of the 21 surveyed grants free registration to their members. All others charge $\$ 50$ to $\$ 750$ for full or active member registration (average of \$465). The CAG was the only association providing free registration to trainee members, who are typically charged a reduced rate of between $\$ 75$ and $\$ 466$ (average \$241). It is common practice for nonmember physicians to pay a higher conference registration rate than members. Although one society charges nonmembers only $\$ 83$, most rates are in the range of $\$ 500$ to $\$ 700$ (average $\$ 681$ ), with a high of $\$ 1,065$. The majority of societies reported using early and late registration fees and having a special rate for attendance of only part of the conference (daily or half-day rate).

These findings indicate that the CAG is well below the norm, especially with respect to registration for the annual meeting, because most other organizations are raising substantial membership-derived funds through registration. This is an important point of which CAG members and its leadership must be cognizant. Should the CAG move to diversify its financial support of the annual meeting? In light of the evolution to distance the medical profession from industry influences, particularly regarding education, many would argue the answer is yes. In addition, sponsorship from the industry waxes and wanes, thus more constant funding sources are desirable. Nonpharmaceutical corporate sources of funding may be an option worth exploring.

These issues have been discussed by the CAG governing board for several years. One of the most obvious solutions involve establishing a successful charitable organization to raise capital to support common goals such as research in

The CAG is proud to acknowledge its Benefactor Corporate Sponsors:
Abbott Laboratories Ltd
ALTANA Pharma Inc
AstraZeneca Canada Inc
Axcan Pharma Inc
Janssen-Ortho Inc
Pfizer Canada Inc
Procter \& Gamble Pharmaceuticals
Schering Canada Inc 
Table 1

Membership categories and yearly fees for 11 Federation of National Specialty Societies of Canada

\begin{tabular}{|c|c|c|c|c|c|c|c|c|c|c|c|}
\hline \multirow[b]{2}{*}{ Membership types } & \multicolumn{10}{|c|}{ National specialty societies } & \multirow[b]{2}{*}{ CAG } \\
\hline & 1 & 2 & 3 & 4 & 5 & 6 & 7 & 8 & 9 & 10 & \\
\hline Full member (certified specialist) & $\$ 335$ & $\$ 257$ & $\$ 100$ & $\$ 300$ & $\$ 435$ & $\$ 450$ & $\$ 455$ & $\$ 150$ & $\$ 200$ & $\$ 450$ & $\$ 200$ \\
\hline Allied health professional (nurses, technicians, etc) & - & - & - & - & $\$ 390$ & - & $\$ 55$ & $\$ 50$ & $\$ 50$ & $\$ 100$ & - \\
\hline Trainee - resident (postgraduate training) & $\$ 110$ & $\$ 15$ & $\$ 0$ & $\$ 38$ & - & $\$ 35$ & $\$ 55$ & $\$ 0$ & $\$ 0$ & $\$ 40$ & $\$ 0$ \\
\hline Seniors/retired members & - & - & $\$ 50$ & - & - & - & - & - & $\$ 0$ & $\$ 60$ & $\$ 0$ \\
\hline Honorary & - & - & - & - & - & - & - & - & - & $\$ 0$ & $\$ 0$ \\
\hline International/corresponding (professional) & $\$ 285$ & - & $\$ 50$ & $\$ 50$ & $\$ 345$ & - & $\$ 110$ & - & - & $\$ 450$ & $\$ 100$ \\
\hline International/corresponding (trainee) & - & - & - & - & $\$ 53$ & - & - & - & - & - & - \\
\hline Corporate & - & - & - & - & - & - & - & $\$ 2,000$ & $\$ 1,000$ & - & $\$ 400$ \\
\hline
\end{tabular}

CAG Canadian Association of Gastroenterology

Table 2

Scientific meeting registration fees for 11 Federation of National Specialty Societies of Canada

\begin{tabular}{|c|c|c|c|c|c|c|c|c|c|c|c|}
\hline Scientific meeting registration & \multicolumn{10}{|c|}{ National specialty societies } & CAG \\
\hline Nonmember (physician) & $\$ 850$ & $\$ 589$ & $\$ 100$ & $\$ 695$ & $\$ 1,065$ & $\$ 943$ & $\$ 700$ & $\$ 550$ & $\$ 685$ & $\$ 1,050$ & $\$ 500$ \\
\hline $\begin{array}{l}\text { Allied health professional } \\
\text { (nurses, technicians, etc) }\end{array}$ & $\$ 250$ & $\$ 214$ & - & - & $\$ 240$ & $\$ 466$ & $\$ 200$ & $\$ 370$ & $\$ 175$ & $\$ 650$ & - \\
\hline Resident/student & $\$ 75$ & $\$ 214$ & - & $\$ 225$ & $\$ 245$ & $\$ 466$ & $\$ 200$ & - & $\$ 145$ & $\$ 375$ & $\$ 0$ \\
\hline International/corresponding & - & - & - & - & - & - & - & - & - & - & $\$ 250$ \\
\hline Early/late registration fees & Yes & No & No & Yes & Yes & Yes & Yes & Yes & Yes & Yes & No \\
\hline Daily rate & Yes & No & No & Yes & Yes & Yes & Yes & Yes & Yes & Yes & No \\
\hline
\end{tabular}

Fees shown are late registration fees. CAG Canadian Association of Gastroenterology

gastrointestinal health and disease. Although the Canadian Digestive Health Foundation has made only modest strides, its potential should not be underestimated. One needs to only look at examples such as the Heart and Stroke Foundation to appreciate what charities can achieve in the arenas of public awareness and education, advocacy, research and fundraising.

Finally, there may be lessons to be learned from the FNSSC survey and its member associations. CAG membership dues have remained constant over the past six years and as noted, are well below the 'industry standard'. We are an outlier among Canadian societies in not charging conference registration for a meeting that is recognized for high-quality, accredited plenary and smallgroup learning sessions. Members have approached the board to recommend means of limiting the degree to which the CAG subsidizes the Canadian Digestive Diseases Week. This might include introduction of a small fee for sessions such as 'Breakfast with the Experts' or the 'Postgraduate Course', to offset meeting costs (eg, meals and audio visual). These and other suggestions are welcome and will be considered as the CAG explores ways to optimize its funding structure.

For more information on the FNSSC and links to its member association Web sites, visit http://fnssc.ca/ 


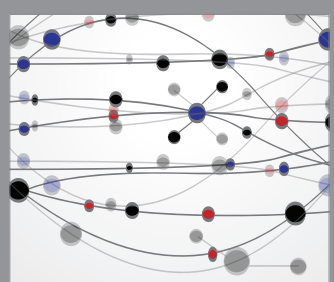

The Scientific World Journal
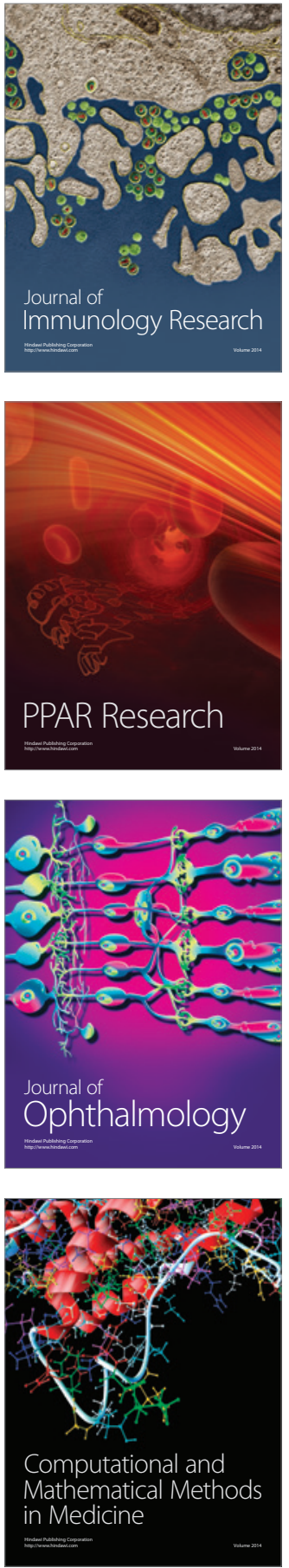

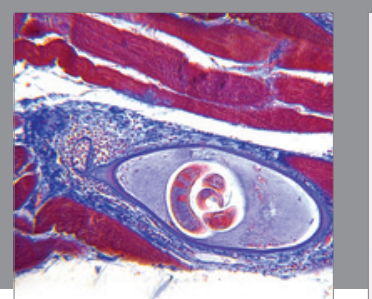

Gastroenterology Research and Practice

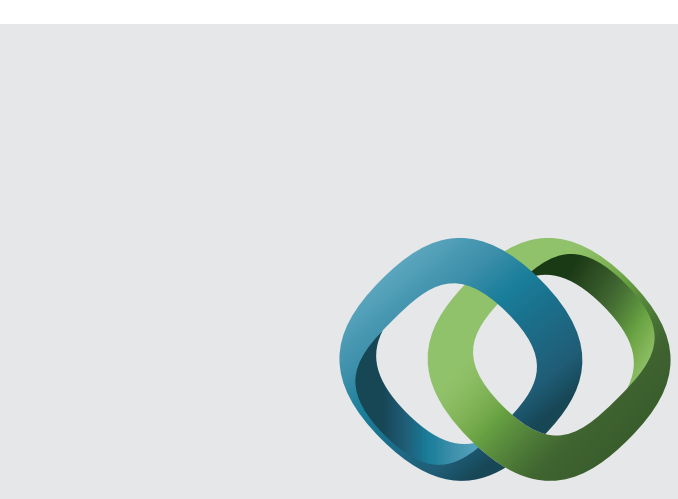

\section{Hindawi}

Submit your manuscripts at

http://www.hindawi.com
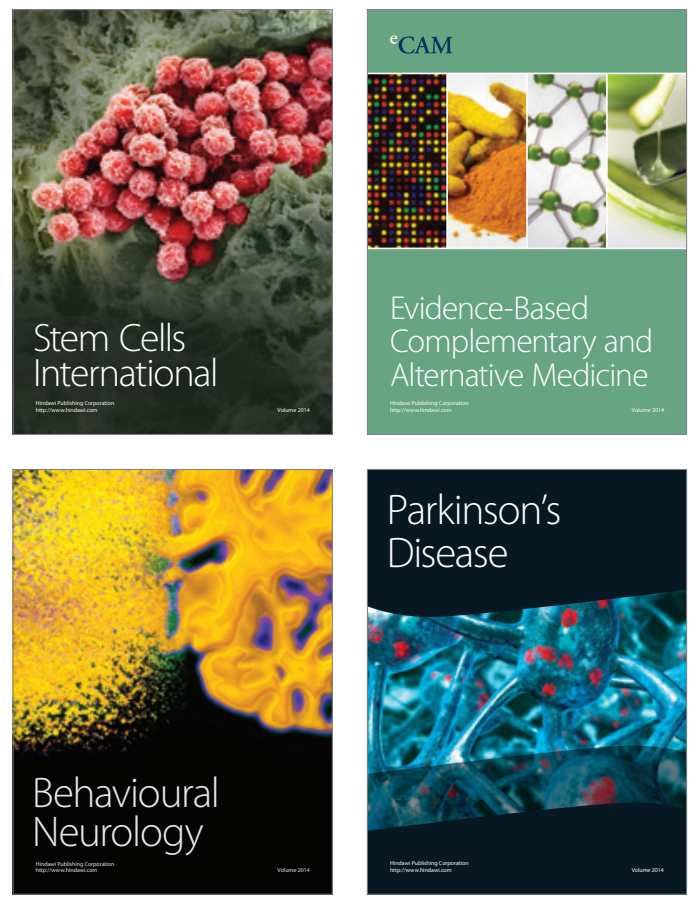
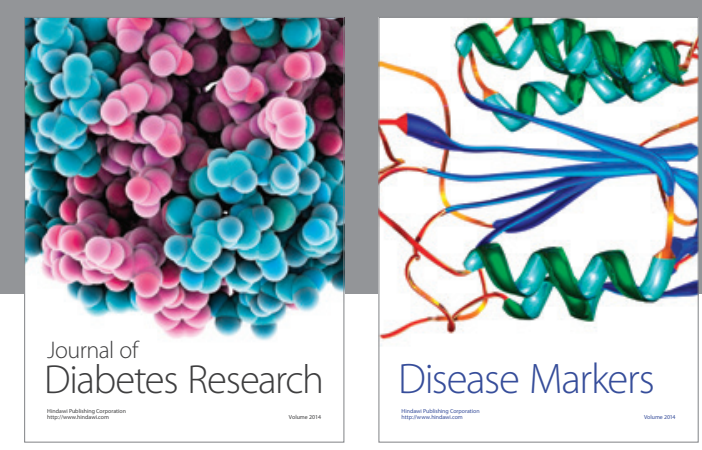

Disease Markers
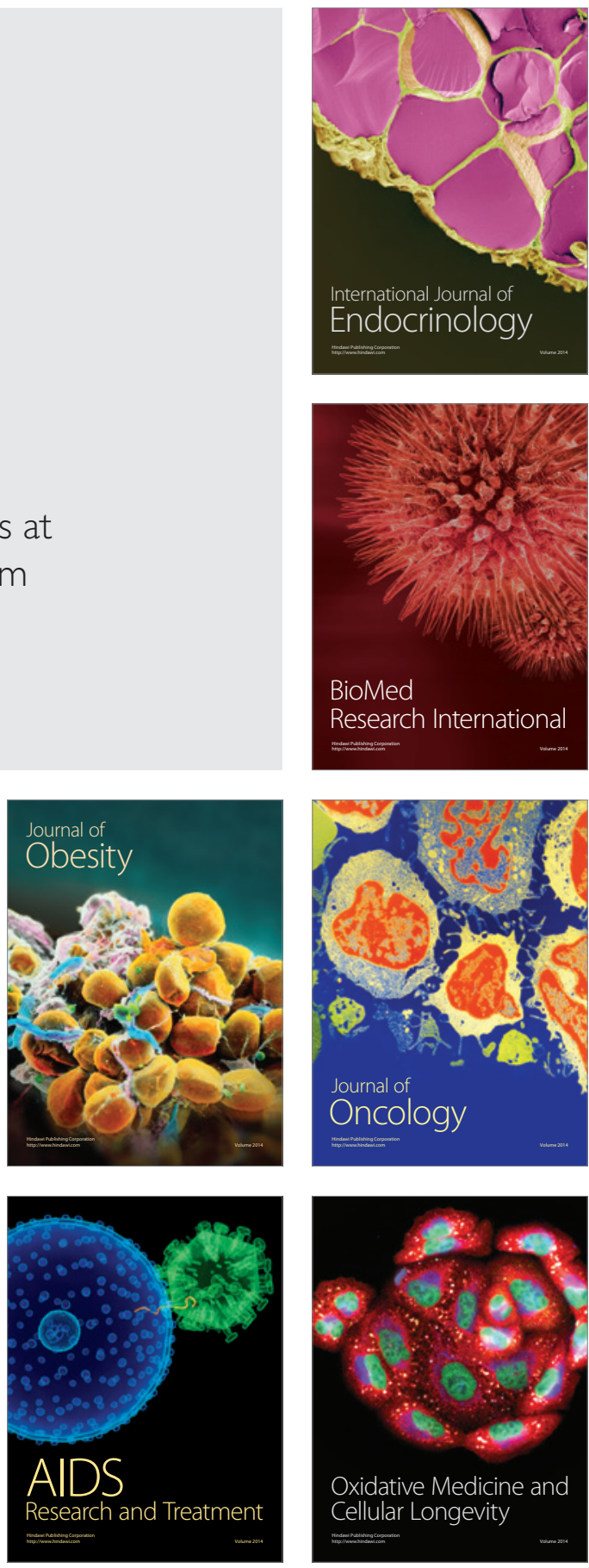